\title{
Utilization of Instagram by Psychiatry Residency Programs in a Virtual Recruitment World
}

\author{
Simone A. Bernstein ${ }^{1} \cdot$ Tara G. Harmon $^{2} \cdot$ Kristina Cabañez $^{3} \cdot$ Chapman Wei $^{4} \cdot$ Jessica A. Gold $^{1}$
}

Received: 20 April 2021 / Accepted: 30 September 2021 /Published online: 19 October 2021

(c) Academic Psychiatry 2021

\begin{abstract}
Objective Many psychiatry residency programs use Instagram to provide information about their program. This study assesses the content and engagement on psychiatry residency program Instagram accounts.

Methods A full list of psychiatry programs was gathered from the American Medical Association Fellowship and Residency Electronic Interactive Database (FREIDA). FREIDA was used to collect demographic information about a program. Program Instagram accounts were reviewed and assessed for content, and engagement scores were analyzed. Univariate and multivariate regression was used to analyze the information collected from the Instagram accounts.

Results There are 109 (42.9\%) psychiatry residency programs with Instagram accounts; 99 (90.8\%) accounts were opened in 2020. Analysis of the content of posts revealed posts with the following themes: $50.5 \%$ were departmental, $21.9 \%$ were social, $14.9 \%$ were other, $10.1 \%$ were academic and professional, and $2.6 \%$ were educational. Using multivariate regression, a higher total number of followers was correlated with the total number of accounts followed $(p \leq 0.001)$ and Instagram stories $(p=0.047)\left(R^{2}=0.579\right)$. Engagement score was correlated with a total number of followers $(p \leq 0.001)$, program size $(p=0.048)$, and whether an account was active $(p=0.003)\left(R^{2}=0.450\right)$.

Conclusion Results demonstrate that 2020 led to an increase in the number of psychiatry residency program Instagram accounts and engagement with followers. Instagram provides a way to further promote a program, yet there is room for improvement to diversify the content.
\end{abstract}

Keywords Social media $\cdot$ Psychiatry residency $\cdot$ Instagram $\cdot$ Recruitment $\cdot$ COVID-19

Due to COVID-19, the American Association of Directors of Psychiatric Residency Training and the Association of Directors of Medical Student Education in Psychiatry recommended psychiatry residency programs offer virtual interviews for the 2020-2021 and 2021-2022 application seasons [1,2]. Typically, an applicant's perception of a program is influenced by in-person interview days where applicants have opportunities to interact with residents and faculty to develop an understanding of the program's culture

Simone A. Bernstein

simone.bernstein@wustl.edu

1 Washington University School of Medicine and BarnesJewish Hospital, St. Louis, MO, USA

2 Indianapolis, IN, USA

3 Austin, TX, USA

4 Staten Island University Hospital, Staten Island, NY, USA
[3]. However, without this opportunity, other recruitment strategies, including social media accounts, were implemented [4].

Social media is a unique method to distribute information and interact with potential applicants. Recent studies in other fields have described the role of social media in recruitment [5-7]. Prior to COVID-19, a survey found that $10 \%$ of respondents reported that information on a program social media profile influenced their residency applications [8]. The most commonly used platform for interactions with programs, at least according to a 2019 evaluation of plastic surgery applicants [9], was Instagram.

Instagram, a social media platform that allows users to share photographs with captions and videos with followers, has seen dramatic growth since its inception in 2010 [10]. The Pew Research Center found that it is used by $67 \%$ of 18- to 29-year-olds, which is the target demographic of many residency applicants [11]. Additionally, the engagement level is 30 times higher than Twitter [12]. To our knowledge, 
no study has looked at Instagram use by psychiatry residency programs.

This study aims to review Instagram accounts of psychiatry residency programs to evaluate the content thematically and determine the most effective engagement strategies for an account. Instagram was evaluated in this study because it has a greater number of residency program accounts than Twitter. On Twitter, there are 46 total psychiatry accounts; of which 26 are solely departmental accounts. We hypothesize that psychiatry residency Instagram pages will have increased in number this past year and help applicants to learn about a program.

\section{Methods}

A full list of psychiatry programs was gathered from the American Medical Association Fellowship and Residency Electronic Interactive Database (FREIDA). FREIDA was used to determine the number of residents in each program, the program location, and whether a program was classified as university-based, community-based, or community-based university affiliated. To find program Instagram accounts, the search feature on Instagram was performed using [ "program name" and "psychiatry residency program"]. Full and abbreviated program names and the specialty names like "psychiatry" and "psych" were used. Based on the description of the account, we omitted accounts that were solely used by the department of psychiatry, not the residency program itself (six accounts).

All Instagram posts were evaluated since the inception of the page during a 1-week period, March 4-10, 2021. Reviewing program pages for a 1-week period was chosen to avoid major changes in page content.

For each Instagram account, the number of followers, number of accounts followed, and posts were found on the account's homepage. Other information obtained from each account included the following: the date of the first post, the total number of posts, and whether the account was active or inactive. An inactive account was one that had no posts since October 2020, the opening of the Electronic Residency Application Service. The content of Instagram posts was further evaluated according to the following themes of the posts: educational, departmental, academic and professional, social, and other. Educational posts informed followers about diseases, mental health, or the history of the field. Departmental posts focused on recruitment, including news and updates for the program, activities like meet-and-greets, or highlights of faculty and residents. Academic and professional posts were focused on research and academic conferences. Social posts showed residents outside of the hospital spending time together at non-work-related events. The posts categorized as "other" did not fit these categories. Other types of posting reviewed were Instagram Stories (highlights that disappear after $24 \mathrm{~h}$ but can be archived on a profile), Instagram Reels (15-s videos with audio, effects, and creative tools), and Instagram TV (videos between $15 \mathrm{~s}$ and $10 \mathrm{~min}$ ). Program websites were also viewed to determine if they linked directly to their residency Instagram page.

An Instagram engagement score (IES) is a tool that measures the engagement of an account using the rate of the total number of likes and comments per number of followers [13]. This score was determined for each program's account. The IES is calculated by adding the likes and comments per Instagram post, dividing the result by the number of followers, and multiplying that result by 100 [13].

The data for this study were verified by two authors. If the information for a particular category varied between two authors, a third author was consulted to review the program Instagram page. Univariate and multivariate analyses were performed to analyze the data using SPSS (version 26; Armonk, NY).

\section{Results}

There were 109 (42.9\%) psychiatry residency programs with Instagram accounts. Since 2020, program presence on Instagram has grown, with 99 (90.8\%) accounts opening in 2020 $\left(R^{2}=0.805\right)$ (Fig. 1). There were 94 active accounts $(86.2 \%)$. For location, the South Atlantic (DC, DE, FL, GA, MD, $\mathrm{NC}, \mathrm{SC}, \mathrm{VA}, \mathrm{WV}$ ) and Mid-Atlantic region (NJ, NY, PA) programs had the greatest percentage of Instagram accounts ( $21.1 \%$ and $20.2 \%$ respectively). For program affiliation, university affiliated $(n=60,55 \%)$ and community programs

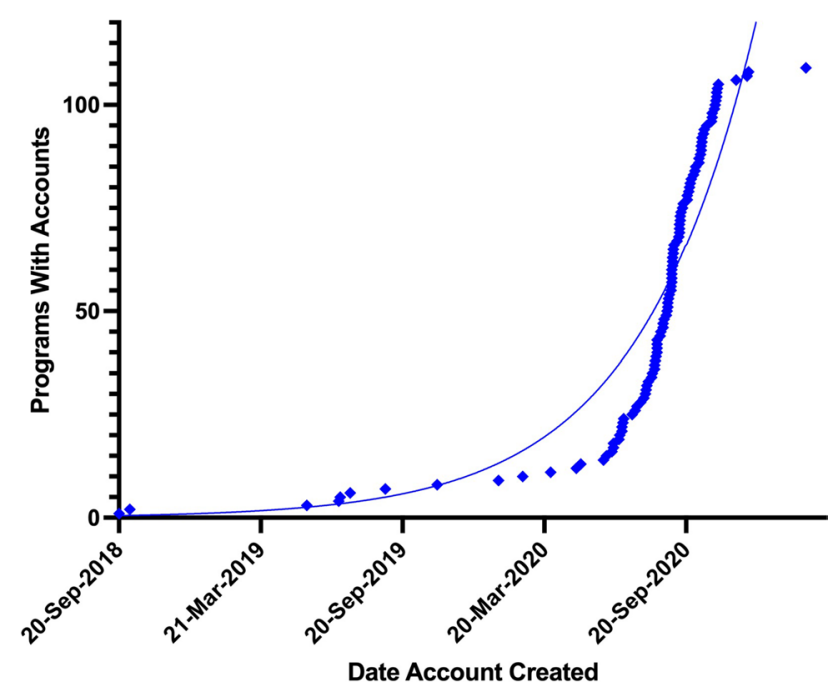

Fig. 1 Psychiatry programs with Instagram accounts $\left(y=0.506 \mathrm{e}^{2.436 \mathrm{x}}\right.$, $R^{2}=0.805$ ) 
with university affiliation $(n=37,33.9 \%)$ had more accounts than community programs had $(n=12,11 \%)$.

For all accounts, the mean number of followers was $400 \pm 223.5$ (range 8-924), and the mean number of accounts following was $153.9 \pm 137.5(0-730)$. The mean number of total posts was $31.9 \pm 22.0(1-95)$. Of all the posts, $50.5 \%$ were departmental, $21.9 \%$ were social, $14.9 \%$ were other, $10.1 \%$ were academic and professional, and $2.6 \%$ were educational. Instagram Stories, Instagram TV, and Instagram Reels were included on the following accounts respectively: $63(57.8 \%), 33(30.3 \%)$, and $0(0 \%)$.

With univariate analysis, a higher total number of followers correlated with a larger program size $(p=0.002$, $\left.R^{2}=0.088\right)$, the total number of posts $\left(p \leq 0.001, R^{2}=0.115\right)$, departmental posts $\left(p \leq 0.001, R^{2}=0.208\right)$, academic posts $\left(p \leq 0.001, R^{2}=0.127\right)$, social posts $\left(p \leq 0.001, R^{2}=0.118\right)$ (Table 1), Instagram TV ( $p \leq 0.001)$, and program affiliation $(p \leq 0.001)$. The location of a program did not significantly affect the number of total followers (Table 1). After adjusting for all variables using multivariate regression, a higher total number of followers was correlated with the total number of accounts they follow $(p \leq 0.001)$ and Instagram Stories $(p=0.047)\left(R^{2}=0.579\right)$.

On univariate regression, a higher Instagram engagement score was correlated with the total number of accounts following $\left(p<0.001, R^{2}=0.111\right)$, departmental posts $\left(p<0.001, R^{2}=0.093\right)$, academic posts $(p<0.001$, $\left.R^{2}=0.099\right)$, social posts $\left(p=0.007, R^{2}=0.066\right)$, and Instagram Stories $(p=0.012)$. After adjusting for all variables using multivariate regression, a higher engagement score
Table 1 Univariate and multivariate linear regression of total followers or Instagram engagement score gained relative to variables

\begin{tabular}{|c|c|c|c|c|}
\hline \multirow[b]{2}{*}{ Total followers } & \multicolumn{2}{|c|}{ Univariate } & \multicolumn{2}{|c|}{ Multivariate } \\
\hline & $p$-value ${ }^{\mathrm{a}}$ & $R^{2}$ & $p$-value & $R^{2}$ \\
\hline Account age & 0.366 & 0.008 & 0.317 & 0.579 \\
\hline Program size by PGY-1 & 0.002 & 0.088 & 0.236 & \\
\hline Total accounts following & $<0.001$ & 0276 & $<0.001$ & \\
\hline Total posts & $<0.001$ & 0.115 & 0.943 & \\
\hline Education posts & 0.916 & $<0.001$ & 0.053 & \\
\hline Department posts & $<0.001$ & 0.208 & 0.271 & \\
\hline Academic posts & $<0.001$ & 0.127 & 0.175 & \\
\hline Social posts & $<0.001$ & 0.118 & 0.427 & \\
\hline Other posts & 0.005 & 0.072 & 0.920 & \\
\hline Active (posts more recent than November 2020) & 0.073 & N/A & 0.117 & \\
\hline Instagram Stories & $<0.001$ & N/A & 0.047 & \\
\hline Instagram Reels & N/A & N/A & N/A & \\
\hline Instagram TV & $<0.001$ & N/A & 0.521 & \\
\hline Program location & 0.504 & N/A & 0.349 & \\
\hline Program affiliation & $<0.001$ & N/A & 0.090 & \\
\hline Instagram engagement score & $p$-value & $R^{2}$ & $p$-value & $R^{2}$ \\
\hline Account age & 0.431 & 0.006 & 0.507 & 0.450 \\
\hline Total followers & $<0.001$ & 0.286 & $<0.001$ & \\
\hline Program size by PGY-1 & 0.001 & 0.777 & 0.048 & \\
\hline Total accounts following & $<0.001$ & 0.111 & 0.297 & \\
\hline Total posts & 0.050 & 0.035 & 0.568 & \\
\hline Education posts & 0.093 & 0.026 & 0.864 & \\
\hline Department posts & 0.001 & 0.093 & 0.553 & \\
\hline Academic posts & 0.001 & 0.099 & 0.552 & \\
\hline Social posts & 0.007 & 0.066 & 0.139 & \\
\hline Other posts & $\mathbf{0 . 0 3 0}$ & 0.043 & 0.526 & \\
\hline Active (posts more recent than November 2020) & 0.251 & N/A & 0.003 & \\
\hline Instagram Stories & 0.012 & N/A & 0.656 & \\
\hline Instagram Reels & N/A & N/A & N/A & \\
\hline Instagram TV & 0.091 & N/A & 0.936 & \\
\hline Program location & 0.917 & N/A & 0.731 & \\
\hline Program affiliation & 0.373 & N/A & 0.629 & \\
\hline
\end{tabular}

${ }^{\mathrm{a}} p<0.05$ is considered statistically significant and bolded 
was correlated with the total number of followers $(p \leq 0.001)$, program size $(p=0.048)$, and whether an account was active $(p=0.003)\left(R^{2}=0.450\right)$. Of the 109 programs with Instagram accounts, 16 programs (14.7\%) included a direct link to their Instagram account on the program website.

\section{Discussion}

Our study investigated the use of Instagram among psychiatry residency programs and described its trend, content, and engagement rate. Based upon our analyses, Instagram has increased in use by psychiatry residency programs since COVID-19, as the vast majority of programs formed their accounts after the announcement of virtual recruitment. As such, Instagram may act as a potential platform, or additional social media avenue, for psychiatry residency programs to recruit applicants.

Program size was associated with the number of followers and engagement of a residency program Instagram account. Larger programs had more followers and a greater engagement score. Beyond simply program size leading to greater alumni networks, there are likely more residents to disperse the time-consuming tasks of managing and updating a page, which can lead to more engagement. Because engagement was found to be correlated with the number of account followers and the number of accounts a program follows, programs of all sizes are recommended to engage with more accounts to help increase their audience. While there is no information to objectively quantify a program's engagement with applicants, previous literature has suggested that having an active social media presence is an important aspect of a residency program because applicants value the additional information when determining whether to apply to or rank a program [14].

Social media accounts promote various characteristics of a program. As departmental, social, and academic posts were correlated with more followers and higher engagement scores, creating more of these posts are opportunities for programs to grow their accounts. Social media can also be used to educate followers about topics within a medical specialty [15]. In a survey of plastic surgery applicants, $89 \%$ were interested in educational content and $98 \%$ wanted to learn about resident life [9]. While educational material could help teach on mental health topics from pharmacology to coping skills, for psychiatry, these posts did not increase the total number of followers or engagement score for psychiatry programs.

While posts are often a primary component of Instagram, fewer programs used the other aspects of the social media platform to increase engagement, including Instagram Stories, Reels, and TV. Yet, the use of Instagram Stories and TV was correlated with an increase in total number of followers.
Programs could benefit from incorporating the use of these Instagram features more into their accounts to increase their followers. They can be used to post brief video tours of facilities and workspaces, interview current residents or alumni, or provide information about day-to-day lives and call experiences.

Limitations of this study include that Instagram was the only platform reviewed. We wanted to go in-depth on the most widely used social media platform in the age range of most resident applicants and one that incorporates photos with all posts. Instagram accounts were evaluated over 2 weeks, so if a program updated its account after this time period, it would not be included in the results. There were also two reviewers, leading to the possibility of subjective bias on evaluation of post categories. This potential bias was minimized with the addition of a third reviewer when there was a disagreement in results.

In conclusion, since the implementation of virtual interviews the past 2 years due to COVID-19, there has been an increase in psychiatry residency program Instagram accounts. Yet, there are still opportunities for more programs to create accounts, incorporate links to these accounts on their websites, post more regularly, follow more accounts, and diversify the content that they post, including the use of high-engagement features like Instagram Stories.

\section{Declarations}

Disclosures On behalf of all authors, the corresponding author states that there is no conflict of interest.

\section{References}

1. Consensus Statement from the Association of Directors of Medical Student Education in Psychiatry (ADMSEP) and the American Association of Directors of Psychiatric Residency Training (AADPRT) on the 2020-21 Residency and Fellowship Application Cycle. Available from: https://www.aadprt.org/application/ files/1015/9009/1630/admsep_aadprt_statement_5-17-20.pdf. Accessed 1 Apr 2021.

2. Consensus Statement from the Association of Directors of Medical Student Education in Psychiatry (ADMSEP) and the American Association of Directors of Psychiatric Residency Training (AADPRT) on the 2021-22 Residency and Fellowship Application Cycle. Available from: https://students-residents.aamc.org/ media/12091/download. Accessed 26 June 2021.

3. Zuo KJ, Retrouvey H, Wanzel KR. Factors that affect medical students' perception and impression of a plastic surgery program. Ann Plast Surg. 2019;82(2):224-8.

4. Bernstein SA, Gu A, Chretien KC, Gold JA. Graduate medical education virtual interviews and recruitment in the era of COVID19. J Grad Med Educ. 2020;12(5):557-60.

5. Goshtasbi K, Tsutsumi K, Berger MH, Kuan EC, Tjoa T, Haidar YM. Otolaryngology residency programs' rising social media 
presence during the COVID -19 pandemic. Laryngoscope. 2021;131(5):E1457-9.

6. Azoury SC, Mazzaferro DM, Piwnica-Worms W, Messa CA, Othman S, Stranix JT, et al. An update on social media in academic plastic surgery training programs. Ann Plast Surg. 2020;85(2):100-4.

7. DeAtkine AB, Grayson JW, Singh NP, Nocera AP, Rais-Bahrami S, Greene BJ. \#ENT: Otolaryngology residency programs create social media platforms to connect with applicants during COVID19 pandemic. Ear Nose Throat J. 2020. https://doi.org/10.1177/ 0145561320983205.

8. Schweitzer J, Hannan A, Coren J. The role of social networking web sites in influencing residency decisions. J Am Osteopath Assoc. 2012;112(10):673-9.

9. Steele TN, Galarza-Paez L, Aguilo-Seara G, David LR. Social media impact in the match: a survey of current trends in the United States. Arch Plast Surg. 2021;48(1):107-13.

10. Walton J. Twitter vs. Facebook vs. Instagram: what's the difference? Investopedia. Investopedia; 2021. Available from: https:// www.investopedia.com/articles/markets/100215/twitter-vs-faceb ook-vs-instagram-who-target-audience.asp. Accessed 1 Apr 2021.

11. Perrin A, Anderson M. Share of U.S. adults using social media, including Facebook, is mostly unchanged since 2018. Pew Research Center. Pew Research Center; 2021. Available from: https://www.pewresearch.org/fact-tank/2019/04/10/ share-of-u-s-adults-using-social-media-including-facebook-ismostly-unchanged-since-2018/. Accessed 1 Apr 2021.

12. Chaffey D, Bullock L. Become a top-performing Instagram, Twitter and Facebook post creator. Smart Insights. 2020. Available from: https://www.smartinsights.com/social-media-marketing/ social-media-platforms/creating-top-performing-posts-on-faceb ook-twitter-and-instagram/. Accessed 1 Apr 2021.

13. Roach A. Instagram engagement: what it is and how to improve it in 2021. Oberlo. Oberlo; 2021. Available from: https://www. oberlo.com/blog/instagram-engagement-improve. Accessed $1 \mathrm{Apr}$ 2021.

14. Fick L, Palmisano K, Solik M. Residency program social media accounts and recruitment - a qualitative quality improvement project. MedEdPublish. 2020;9(1).

15. Chang TN-J, Hsieh F, Wang Z-T, Kwon S-H, Lin JA-J, Tang ET-H. Social media mediate the education of the global microsurgeons: the experience from International Microsurgery Club. Microsurgery. 2018;38(5):596-7.

Publisher's Note Springer Nature remains neutral with regard to jurisdictional claims in published maps and institutional affiliations. 